\title{
Article
}

\section{Negotiating the cultural and economic outcomes of sport heritage attractions: the case of the National Baseball Hall of Fame}

\author{
Ramshaw, Gregory, Gammon, Sean James and Tobar, Felipe
}

Available at http://clok.uclan.ac.uk/31581/

Ramshaw, Gregory, Gammon, Sean James ORCID: 0000-0001-5053-8763 and Tobar, Felipe (2019) Negotiating the cultural and economic outcomes of sport heritage attractions: the case of the National Baseball Hall of Fame. Journal of Sport \& Tourism, 23 (2-3). ISSN 1477-5085

It is advisable to refer to the publisher's version if you intend to cite from the work. http://dx.doi.org/10.1080/14775085.2020.1715825

For more information about UCLan's research in this area go to http://www.uclan.ac.uk/researchgroups/ and search for <name of research Group>.

For information about Research generally at UCLan please go to http://www.uclan.ac.uk/research/

All outputs in CLoK are protected by Intellectual Property Rights law, including Copyright law. Copyright, IPR and Moral Rights for the works on this site are retained by the individual authors and/or other copyright owners. Terms and conditions for use of this material are defined in the policies page. 


\title{
Negotiating the Cultural and Economic Outcomes of Sport Heritage Attractions: The Case of the National Baseball Hall of Fame
}

\begin{abstract}
Contemporary museums must balance their roles as commercial entities and repositories of various, and often dissonant, heritages and histories. Sports museums in particular often have clear commercial and nostalgic aims, particularly through tourist visitation, though the extent to which they represent more challenging narratives remains unclear. This paper examines how one of the most famous sports museums in the world, the National Baseball Hall of Fame (NBHF) in Cooperstown, New York, balances its dual role as tourist attraction and repository of baseball's sometimes checkered past. It was found that different sections of the museum provide greater or lesser degrees of engagement with more controversial issues, although the commercial outputs and appeal of the museum remains clear throughout. Utlimately, the NBHF demonstrates that balancing veneration and critique in collections can be commercially prosperous, and can provide a template for other sport and popular culture museums who may be wary of incorporating more challenging narratives in their exhibits. Furthermore, the symbiotic relationship between the Hall of Fame and the village of Cooperstown, particularly in creating and maintaining cultural and economic outputs, requires further exploration.
\end{abstract}

Key Words: Baseball, Cooperstown, Museum, Sport Heritage, Sport Tourism 


\section{Introduction}

Graham, Ashworth and Tunbridge (2000) argue that heritage can be seen as a duality of economic and cultural capital. Graham (2002) further articulates the economic and cultural uses of heritage, noting that heritage is a "primary component of strategies to promote tourism, economic development, and rural and urban regeneration” while simultaneously being "a knowledge, a cultural product and a political resource" (p. 1006). Many heritage sites must negotiate both their economic duties, including generating on-site revenue as well as contributing to local tourism development, along with their cultural roles in accurately and authentically representing a multiplicity of pasts. The degree to which heritage sites are able to negotiate these tensions will vary, though some sites appear to be able to negotiate these more easily than others. Sport heritage sites and, in particular, sports museums, have increasingly been faced with the need to address both their cultural and economic aims, which often must balance their role as tourism venues for uncritical and popular forms of nostalgia while also often addressing or (re)presenting the challenging issues of the sporting past. In particular, Vamplew (1998) argues that many sports museums are based on a false nostalgia which fetishizes a "golden age" of a sport, often overshadowing or ignoring more subtle or critical approaches in order to appeal to a mass audience. However, many sports museums have had to become more than outlets for nostalgia, given the complexity of the sporting past (Ramshaw \& Gammon, 2005). That said, while some sports museums are able to blend celebratory and critical narratives (see: Phillips, Osmond \& Morgan, 2014), most sports museums - and sport heritage sites in general - typically avoid more contentious approaches, opting instead for celebratory narratives which augment their commercial aims and outputs. 
Phillips' (2012) sports museum typology suggests that a sports museum's broader purpose, funding model, management approach, and whether the collection is for public or private consumption, will often determine how the sport's past is represented and interpreted. While Phillips (2012) notes that publicly funded museums, such as generalist national museums, can take more critical approaches to the sporting past given that they are not primarily reliant on revenue from admissions and souvenir sales, corporate sports museums (such as team or league museums) typically exhibit more celebratory narratives and do not often address more contentious subjects. However, for many sport heritage sites, omitting or ignoring more critical moments from the past - particularly if they are broadly known by both fans and non-fans alike risks the legitimacy of the site as a repository of a sport's past. Such is the case with baseball and, in particular Major League Baseball (MLB), where the sport's remarkable heritage of great players, teams, and performances intermingles with issues such as labour disputes, the use of Performance Enhancing Drugs (PEDs) and illegial narcotics by players, and gambling on games by players and managers. Legendary names such as Ruth, Gehrig, Robinson, and Clemente are commonly known for their deeds both on and off the field, while more recent players - such as Rose, Bonds, and McGuire - are equally famous, though their legacies are significantly more contentious given their association with some of the sport's recent controversies noted above.

As such, this paper examines the negotiation of cultural and economic considerations at the National Baseball Hall of Fame (NBHF) in Cooperstown, New York. In particular, this paper argues that, though the NBHF is relatively unique in terms of corporate sports museums in that more controversial, contentious, and melancholy aspects of the sport's past are represented, more celebratory narratives are ultimately the museum's focus as there is a clear link between the museum as a "shrine" and the economic outputs of the museum, both at the NBHF itself and in 
the Cooperstown village more broadly. Ultimately, the NBHF provides a strong case for other sports museums and halls of fame to provide a more robust narrative, as there is little to suggest that such an approach - particularly in terms of representing the sport's more recent and remembered past - has significantly harmed the NBHF's economic outputs or cultural legitimacy. However, the degree to which the NBHF deals with contentious pasts appears to be framed largely around recent issues, many of which would be in living memory of visitors. More distant controversies receive relatively little consideration, while both the "shrine" of the hall of fame section of the museum, as well as the commercial aspects both in the museum and in the surrounding village of Cooperstown, largely ignore more contentious topics. Specifically, the NBHF does represent controversial topics from baseball's past, primarily from the past two generations of the game, including players' drug use, labour issues in the sport, gambling, and the use of PEDs which are represented as ongoing concerns and controversies, while other controversial topics - such as racism and sexism - are largely positioned as "historical" and therefore mainly confined to the past. While the NBHF encourages visitor input on topics such as Pete Rose's induction into the NBHF, as well as how players with links to PEDs should be considered, few opportunities for debate and discussion exist in other parts of the museum. The section of the museum that represents the "eternal" aspects of the sport - the shrine of the NBHF - is socially and spatially created as a sacred space, with no room for debate and which encourages visitors to quietly worship the eternal heroes of baseball's past. Furthermore, the economic aspect of the NBHF, the large shop that is accessible immediately once visitors exit the "shrine" of the hall of fame is almost exclusively "eternal"-centric with souvenirs of baseball's shrine (rather than its history) available for purchase, while visitors emerge into the quintessential nostalgic American village of Cooperstown following their visit and may visit any 
number of baseball memorabilia stores to which dissonant pasts are absent. Therefore, this paper is an exploration of a globally significant sports museum collection to see how narratives of veneration and critique are addressed, balanced, or ingored. The NBHF was chosen as the venue for this exploration both because of its history and global reputation, as well as because the sport heritage it represents is simultaneously widely-venerated, particularly nostalgically, and problematic, owing to the sport's checkered past.

\section{Literature review}

This literature review focuses on the economic and cultural discourses constructed about the NBHF and Cooperstown, New York. Cooperstown is a picturesque American village that was first inhabited by members of the Iroquois Confederacy (Newman, 2001) and later by European settlers (Falk, 2012) and is the home of a number of different touristic sites besides the NBHF including the Farmer's Museum, the Fenimore Art Museum, Hyde Hall, and the Glimmerglass Opera (Fyfe, 2008). The village also sits on the banks of Lake Otsego, which has hosted leisure tourism since the mid-nineteenth century (Falk, 2012). However, it is Cooperstown's connection to the supposed beginnings of baseball in America which has made the village famous (Gould, 1989; Blinde \& McCallister, 2003; Fyfe 2008). According to legend, Abner Doubleday, a former captain in the Union Army, invented baseball at Cooperstown in 1839. While it is widely accepted (including by the NBHF itself) that baseball was not, in fact, invented in Cooperstown, the village remains the symbolic home of the sport, and the keeper of its most treasured heritage. According to Friss (2006), the so-called "Doubleday myth" was fueled by many Americans' desire for creationist myth, with one of the results being that Cooperstown became the home to a particular form of pilgrimage. The village encouraged this form of tourism, beginning with the 
opening of Doubleday Field in 1934 and, five years later in 1939 on the reputed one hundredth anniversary of the creation of baseball, the NBHF was opened which became the primary catalyst in the transformation of the community into primarily a baseball tourism location.

According to Blinde and McCallister (2003), the NBHF has been described as a kind-of national shrine, while Newman (2001) suggests it has come to be understood as a type of secular pilgrimage site. Other authors, including Allen and Parsons (2006) and Friss (2006), suggest that the NBHF is one of the most well-known and mimicked halls of fame in the world, which is remarkable given the site's relative isolation. As Newman (2001) notes, the village has lacked through much of its history major roads and railway system, while the closest airport of any note is two hours drive away. That said, as both Fyfe (2008) and Anania (2016) note, the NBHF's isolation has not diminished its tourism impact, with approximately 300,000 visitors making the trek to Cooperstown annually.

Increased tourism in Cooperstown has changed the face of the village itself. The main catalyst for the changes was the increase and, in recent years, decline of the baseball memorabilia trade along the Main Street corridor. Most recently, the threat to the baseball memorabilia market has been the creation of the Cooperstown Dreams Park, a large baseball tournament facility located five miles outside of Cooperstown, which also offers a wide range of food services and baseball stores, which has had an impact on the number of visitors staying, dining, and shopping near the NBHF. Anania (2016), for example, notes that the introduction of the Cooperstown Dreams Park has coincided with a decline in the number of baseball souvenirs stores along Main Street (although this could also be explained by the higher taxes and rental rates along the Main Street corridor). Additionally, preservation and zoning laws have been imposed within the village iteself, maintaining architectural integrity, upkeep of shops (Falk, 
2012; Anania 2016), and prohibiting commercial chain stores or restaurants to establish at Main Street (Fyfe, 2008), though these regulations do not apply to the Cooperstown Dreams development.

However, undoubtledly Cooperstown and its Main Street have prospered because of the NBHF, although to what extent it has prospered is a matter of disagreement. Falk (2012), for example, argues that the cultural heritage and small-town nostalgia of Cooperstown has actually been threatened by the abundance of baseball heritage. Similarly, Fyfe (2008) contends that the idyllic pastoral landscape of Cooperstown is now little more than a commercialized mecca for baseball merchandise and collectibles. However, others note that without the NBHF and the associated businesses in the village, it is unlikely that Cooperstown would benefit from tourism as much as it has (Anania, 2016).

Whilst tourism-based studies tend to place emphasis on the diverse impacts that visitor attractions have upon the destinations in which they are situated, fewer studies acknowledge the extent in which the place influences how the attraction is perceived. For example, the reverence and iconicity in which the NBHM is held amongst the baseball fraternity has a lot to do with where the attraction is located. More specifically, in some cases the place has the potential to influence how those that visit the attraction go on to interpret them. For example, research undertaken by Ram et al (2016) found that, ““(t)ourists’ perceptions of attractions in terms of authenticity are partly dependent on where the attraction is located, i.e., the level of the destination heritage experience" (p. 116). In terms of Cooperstown, such effect transcends its rather fragile links to the origins of the game - and more on the traditional, conservative and bucolic idyll that it exudes. It is hard to imagine that any attraction espousing unconventional or radical interpretations on any subject would sit well within the picturesque surroundings of this 
famous village. Furthermore, it is worth considering to what extent Cooperstown's reputation and environment indirectly influences the manner in which the NBHF presents and interprets the many exhibits and stories it houses.

This is not to suggest that there is a deliberate manipulation taking place - only to bring attention to the significance that the immediate location could have upon the decisions made at the NBHF. Clearly, both the village and the museum are inextricably linked, in particular by what the village symbolises. The influence of dominant culture on museum interpretation is not new (Barranger \& Flynn, 1998; Pearce, 1992) but studies that acknowledge the influence of the immediate location have had significantly less attention. As detailed above, visitors display a notable affective attachment (Williams, 2002; Yuksel et al, 2010) towards the village that appears to be an integral part of the NBHM experience. Indeed, it could be contended the building itself is both a cultural and architectural extension to Cooperstown.

Several authors (Friss, 2006; Ogden 2007; and Kelly 2007) argue that the NBHF, throughout much of its history, avoided discussions about marginalization (in particular, racial discrimination) in baseball. Friss (2006), for example, notes that that it was thirty-three years between the inauguration of the NBHF and the display of the first artefacts related to Negro Leagues players, while Ogden (2007) points out that the opening of the exhibit dedicated to African American baseball players happened only in 1997, coinciding with the retirement of Jackie Robinson's \#42 throughout professional baseball. Despite the inclusion of broader narratives about baseball's past, in particular those which removed an overtly nostalgic narrative, issues remained. Kelly (2007), for example, notes that when more than a dozen Negro Leaguesera players were inducted into the NBHF in 2006 (along with pitcher Bruce Sutter, who was not 
a Negro Leagues player), the NBHF press released announced, "Ace reliever and 17 Others Inducted into National Baseball Hall of Fame.” However, Parsons and Allen (2006) maintain that race does not have any appreciable effect on the odds of a player being elected to the NBHF and that the election to the hall of fame still is based, to a very large extent, on meritocratic principles. Representations of gender at the NBHF have also been explored. Blinde and McCallister (2003) argue that the NBHF is a male-dominated domain with women's impact in baseball being largely treated with derision by visitors. Other issues which are part of the current NBHF narrative, such as drug use in baseball, have received nominal research attention, at least in terms of NBHF induction. Von Burg and Johnson (2009) suggest that the Mark McGuire case (McGuire set the single season home run record in 1998, but was later suspected to have taken PEDs throughout much of his career) who was the first player from the so-called "steroid era" of baseball to be considered for hall of fame induction, set the precident for subsequent players who had taken (or were suspected of taking) PEDs and found that it was unlikely that players of this era would be inducted into the NBHF.

Fundamentally, such decisions derive from the beliefs of the organization. Davies et al (2013:346) argue that "organisational culture plays an important role in shaping behaviour in museums." More specifically they highlight that a museum has a decision to take on how it communicates its values. Does it see itself as a temple for housing precious objects, a forum of social debate, a leader of social change, or predominantly as a commercial entity that is content to be led by the customer? As indicated at the beginning of this paper, these questions were very much in the forefront of this research, and provided a clear focus of what areas in which to first explore. 


\section{Methodology}

Data collection at the NBHF took place in January 2018, with the researchers visiting the site and surrounding village on six consecutive days. Visiting the location in the offseason provided a unique research opportunity, as there were days when the researchers had the museum entirely to themselves. Using Yin's (1994) case study method, three data sources were used: informal, unstructured conversations with museum staff (Veal, 2006) textual/material analysis (Slater, 2006) and observations and field notes (Patton, 2002). According to Patton (2002), "using a combination of observations, interviewing, and document analysis, the fieldworker is able to use different data sources to validate and crosscheck findings" (p. 306). Informal conversations with five museum staff (specifically gallery gudies and interpreters) predominantly focused on their understandings and impressions of contentious narratives at the museum, how long visitors tended to stay at the museum, and whether visitors spent much time at the museum shop or in the surrounding village. Museum staff were also asked about their own opinions of historical or contemporary issues and topics, which they were permitted by museum management to provide. Conversations with museum staff were not recorded or transcribed verbatum, but notes based on conversations were taken by the researchers then discussed and compared at the end of each day. Informal impromptu conversations also occurred with other visitors at the museum, although given the time of year there were very few visitors of any kind. Textual-material analysis focused on promotional material, such as the NBHF website and social media postings (specifically through NBHF's Facebook and Twitter feeds). Pre-visit, the promotional material helped to contextualize the NBHF's outreach and marketing approaches, specifically how it presents itself to the public. Misiura (2006) contends that marketing heritage is different than marketing other 
commercial products, in particular in balancing commercial aims (such as visitation, events, and on-line retail) and broader cultural aims (such as conservation, public education, and awareness). In this, the NBHF promoted both commercial (visitation, shopping, membership, events) and cultural (important anniversaries, artefacts, hall of fame inductees, curatorial decisions) through their promotional channels. Analyses of these texts provided content for narratives, as well as background and contextualization for observations and museum staff discussions (Silverman, 2001). Using Bailey’s (2007) observation guidelines, observations and field notes included descriptions of museum spaces and exhibits, themes and impressions of the museum's collections, and observations of patrons as they explored the museum. This included space dedicated to particular topics and issues, observations of museum visitors as they explored the museum as well as placement of museum staff, museum layout and routes, lighting and age of exhibits, age of artefacts, and discursive themes (eg.: veneration, contestation, explaination, justification) within museum exhibits and interpretation. Data from this study was coded manually, as the amount of raw data was manageable enough to not require a software program. Based on data analysis, four themes developed: the museum as repository, museum as forum, museum as shrine, and commerce and Cooperstown. The metaphor of the baseball diamond and progression of the player through the diamond (first base, second base, third base, home) is used as a metaphor for the progression of the visitor through the NBHF exhibit spaces.

When addressing particular forms of heritage, particularly sport heritage that so often can be intricately linked to notions of personal and collective identity, it is worth noting the perspectives of the researchers involved in the study. One researcher is a baseball fan, growing up in North America, who is broadly familiar with the history, major players, and controversies of the sport. The other researchers are not from the United States and, though knowing some of 
the background to the sport, had limited exposure to the sport and its history. The study was led by the "insider," which we felt provided an advantage in that he could provide context and cultural memory, while the "outsiders" did not carry extensive cultural baggage when visiting the site or engaging with the baseball literature and could raise topics and issues that would have otherwise been overlooked.

However, it is important to note that the study took a reflexive iterative approach, whereby the research team would meet up at the end of each day to discuss their experiences and findings. (Srivastava and Hopwood, 2009:77; Taylor and Rostron, 2018; Weed, 2007) Any observations and conversations encountered at the NBHF that were deemed significant would be first compared to the literature - and then shared, culminating in more refined objectives the following day. For example, after the first two visits the topic of "tone" was discussed that led to a decision to explore the tonal variances within, and between, the spaces and themes at the museum and hall of fame. Also, the personal positions of the guides were questioned, that led to further informal interviews that aimed to ascertain whether they were willing and able to share their own beliefs related to issues in the game - or whether they had to tow the party line. Related to this point was an uncertainty over the NBHF's independent authority; that it was unclear whether curatorial decisions were based upon expertise and organizational policy, or predominantly influenced by the current opinions of the visitors and fans. In short, did the NBHF act as signpost or weathervane? Lastly, during all the visits, the research team discussed what part nostalgia played in the choice and presentation of the exhibits, as well as the accompanying narratives that supported them. Was it the researchers' personal emotional responses to these exhibits - or was there a deliberate strategy to present and communicate baseball's past in an overly romantic manner? This inter-reflexive practice (Barratt and Mills, 2018) created a more 
holistic and multi-dimensional treatment of the case study. Reflexion was both internal and shared, which helped hone and validate specific ideas that would have otherwise been missed or deemed unimportant.

\section{Lead-off Hit - Museum as Repository}

Much of the NBHF's exhibit space is dedicated to the sport's history up to the early 1970s. Elements of baseball's development as both a codified sport and as a central part of American leisure and identity, early player equipment, past champions and notable teams, and player records and accomplishments, all form the basis for much of the narrative. Although many players feature in the exhibits in the pre-1970s period, significant gallery space is awarded to four major baseball figures: Babe Ruth, arguably the greatest and most famous baseball player of all time (Figure 1); Connie Mack, the most successful manager of all time; Roberto Clemente, perhaps the greatest Latin American baseball player of all time whose life was tragically cut short in an airplane crash while on a humanitarian mission in Puerto Rico in 1972; and Hank Aaron, a legendary player whose career began in the Negro Leagues and finished as baseball's all-time homerun leader (until Barry Bonds broke his record in 2007). Outside of Connie Mack, who may only be known to baseball fans, Ruth, Clemente, and Aaron are all widely recognized names outside of the sport as well as being revered by baseball fans. In highlighting these figures in particular, there appears to be a balance between pleasing both dedicated fans as well as engaging (and, perhaps, not alienating) casual or non-fans. Given that the NBHF hosts approximately 300,000 visitors per year (although, this figure may vary year-on-year, and is often dictated by which players are inducted into the hall of fame each year) (Bloom, 2018), it seems likely that many of the visitors have limited knowledge, or perhaps interest, in baseball 
and are visiting because a friend or relative (who may be a baseball aficionado) wanted to see the museum.

Figure 1 - Babe Ruth exhibit at the National Baseball Hall of Fame. Ruth is one of the few baseball figures provided significant individual space in the museum's galleries. Photo by (Removed for Review)

The historical sections of the museum also include narratives about Latin American players (;Viva Baseball!), women in baseball (Diamond Dreams), and African-American players and leagues (Pride and Passion). Each of the sections includes artefacts and interpretive text about the history of certain leagues and figures from each of these important, but often overlooked, aspects of the sport's history. There are aspects of segmentation both literally and figuratively in these exhibits - each exist outside or as parallel to the "regular" narratives about baseball's greatest stars and teams. While the focus of the narratives often includes descriptions of exclusion, there is also a positioning of racial or gender biases in baseball as, in fact, historical narratives are not necessarily always part of the contemporary sport. The narrative in the Pride and Passion exhibit, for example, ends in the late 1950s, and though there is a brief note at the end of the exhibit about some racial issues continuing today (next to a Chicago White Sox jacket worn by President Obama), the positioning of the exhibit is that many racial issues ended with the desegregation of baseball. Similarly, the Diamond Dreams exhibit predominantly focused on the women's baseball leagues which were created during the Second World War (and to which many casual or non-baseball fans would be familiar with through the 1992 film A League of Their Own). 
Unlike other sections of the museum which inspire a degree of dialogue and discussion, particularly those which focus more on contemporary teams and players as well as those which engage a degree of nostalgia, the historical sections of the NBHF are largely a monologue. In essence, the exhibits were about the foundations of the game, some of its major figures, and some of the parallel tracks which ran alongside big-league baseball. Even those moments which could inspire dialogue about contemporary issues, such as the 1919 Black Sox betting scandal when eight players - including the infamous Shoeless Joe Jackson - were found to have received bribes to lose the World Series, were treated as historical footnotes. In part, there are likely fewer visitors with any degree of first-hand experience in seeing many of the players featured in these sections of the museum. Those impressions that were received were largely to be second hand, and hardly the stuff of first-person nostalgia. Indeed, it is not long now until there will be no living memory of Babe Ruth. Interestingly, compared with the other sections of the museum, there appeared to be relatively few gallery guides present in the historical sections as well.

However, far from being obligatory, these sections both add gravitas to the other sections of the museum as well as being engaging in their own right. After all, one need not be an Egyptologist to visit the British Museum and appreciate the Rosetta Stone. Having these sections and their related artefacts certainly solidifies the museum's cultural capital. It is not only the home of baseball (Doubleday myth aside), but also a repository of important artefacts in American social and cultural history. These sections also solidify the economic duties of the museum. The importance of the artefacts also means that they need to be viewed and to be experienced in person, leading some visitors to refelect on their own pasts. For example one visitor who had come with his son and grandson was particularly taken by a bat, commonly used 
in the 1940s and 50s: "Hey that's the bat I used - I'll be damned!". The three of them stared at the bat in silnce before slowly moving on to the next exhibits.

The tone of the sections, particularly in comparison with the contemporary sections which inspire more controversy and, therefore, dialogue - and the hall of fame shrine - which inspires more reverence and nostalgia - the real purpose of this section is to learn, not that the past informs the present but rather that it is interesting and important in its own right. The fact that the sections are frozen in a time lock is, as noted above, problematic to a degree. Inequities about race and gender are still part of the contemporary game. African American participation in baseball is at a generational low, something actually highlighted in contemporary exhibits at the museum, while women remain largely absent in the professional game. Only Latin American baseball players and managers seem to have thrived in contemporary baseball. Perhaps it is no coincidence then that the ;Viva Baseball! exhibit leads into one of the main galleries about the contemporary baseball.

\section{Rounding Second - Museum as Forum}

While the historical displays in the NBHF might be considered a blend of academic lecture and hagiography, the sections which cover the 1970s to the present could be considered a combination of comforting nostalgia with the harder truths of an acquired heritage. While many of the exhibit spaces have a blend of different narratives, those such as The Locker Room (which includes contemporary artefacts from all current MLB teams), Whole New Ballgame (which covers the 1970s to the present), Baseball at the Movies (which covers baseball in cinema and television), Scribes and Mikemen (which looks at baseball writers and broadcasters), Sacred Ground (which covers historical and contemporary baseball stadia), and Autumn Glory (which 
covers the World Series champions) are particularly focused on recent baseball history. The fact that the period discussed in these exhibits exists in living memory for many visitors adds an additional, personal narrative to the experience which may not be there when viewing exhibits about the late nineteenth or early-to-mid twentieth centuries. Here, Bagnall's (2003) idea of heritage performance becomes more realized, as the performance becomes a dialogue between visitor and artefact/exhibition, and visitors with one another. A committed baseball fan, in this case, can convey personal memories about particular games, players, and stadia often as part of a shared nostalgia with other visitors. However, this section provides an intergenerational and intercultural dialogue as well. Fans can communicate their memories to others, particularly to their children and to non-baseball fans (say, to a spouse), providing a kind-of existential authentic experience (Wang, 1999). Baseball fans in these sections of the museum have greater opportunities to, for example, share their memories about watching the "Big Red Machine" Cincinnati Reds of the 1970s, or remember going to a game at the old Comisky Park in Chicago with mom or dad, or recall listening to Ernie Harwell call Detroit Tigers games on the radio late into a summer's night, or share a memory about watching the 1988 World Series on TV and seeing a hobbled Kirk Gibson hit a miracle pinch hit homerun. As such, the power of these spaces and artefacts are not necessarily just as important in telling the story of baseball, but rather telling the story of baseball to one another.

Although nostalgia is often the central feature of many sport heritage attractions, part of the living memory of recent eras of baseball include the sport's many issues. Gambling, labor issues, controversial players and records, illegal drug use, issues with stadium development, and the use of Performance Enhancing Drugs (PEDs) such as steroids by players are all a part of the heritage and legacy of contemporary baseball (Figure 2). In this, the NBHF elects to balance 
both the appeal of nostalgia - both personal and shared - with a factual, and often critical, look at the sport's recent issues. Here, the museum inspires debate, discussion, and opinion. Not surprisingly, sections such as Whole New Ballgame also have a number of gallery guides present who, uniformly, noted that though they have to provide the NBHF policy on controversial issues, they were also free to debate and discuss issues - and were permitted to include their own personal opinions as well. Not surprisingly, the guides unanimously said that the two topics visitors wished to discuss most were Pete Rose - the all-time leader in hits who was banned from MLB (including for induction into the hall of fame) for gambling on games - and players who used (or are suspected of using) PEDs and their eligibility for hall of fame induction. Even sections such as Sacred Ground which, ostensibly, is a nostalgic look at old ballparks, nevertheless questions the decisions to create multipurpose symmetrical stadia in the 1970s and 80s (in many cases to the detriment of historic stadia), while also critiquing the retro stadia trend (which used heritage aesthetics in stadia design) as a depthless simulacrum of authentic stadia.

Figure 2 - Signage in the galleries noting the hall of fame's policy about representing players suspected of taking performance enhancing drugs. Photo by (removed for review)

\section{Touching Third - Museum as Shrine}

Unlike the historical and contemporary galleries, the actual hall of fame space - where the bronze plaques of enshrined members reside, is both the space that generates the most discussion and controversy outside of the museum (particularly in terms of who belongs and who does not) and the space within the museum which appears most devoid of controversy. The layout of the hall of fame section is similar to that of a church or temple - with plaques lining each side of the 
space, divided by eras of induction, leading up to the central altar - the initial induction class in 1936: Babe Ruth, Ty Cobb, Walter Johnson, Christie Mathewson, and Honus Wagner (Figure 3). All plaques are the same size, suggesting that all who are enshrined in the hall are equal (save, perhaps, for the placement of the initial class), and are made of bronze suggesting a permanence not found in other sections of the museum. The space is also very quiet, even when there are other visitors present. Guides who were often present in the hall would reinforce its sanctity by approaching visitors, and whispering to them in hushed tones whether they were there to see a particilar hall of famer. One of the researchers was usherered around the hall, and given a full account of the hall's history, as well as directions to the more famous of its incumbents. In this part of the attraction, the role and behavior of the guide changes - from objective informer to a keeper and protector of all who's plaques adorn the walls. They become less of guide, and more of a verger.

Although visitors will take photos of different plaques, perhaps those which are particularly famous such as Jackie Robinson or Lou Gerhig or inductees from their home team, or point out particular player plaques to their party, there is a sense of hushed reverence. Adding to the sense of sanctity is the fact that whichever issues or controversies the inductees may have had, their sins are effectively wiped clean through induction. For example, one of the exhibit spaces leading into the hall of fame section of the museum includes small displays honouring the most recent class of inductees. In January 2018, the space included exhibits to 2017 inductees Tim Raines, who admitted to cocaine use during his career (including during games), Craig Biggio, who was suspected of using PEDs during his career, and Ivan Rodriguez, who was also linked to PED use (Nightengale, 2017). Unlike the Whole New Ballgame section of the museum, these issues are not part of these exhibits, nor are they mentioned on the inductees' plaques. 
Figure 3 - The temple/shrine-like hall of fame space. The inaugural inductees are middle-centre and marked by an American flag. Photo by (removed for review)

\section{Heading for Home - Commerce and Cooperstown}

Upon leaving the hall of fame section of the museum, visitors encounter a large hall of fame store. Although the museum spaces are a combination of temple and forum, the museum store focuses almost exclusively on the hagiographic and nostalgic. The museum even has its own line of retro/nostalgic clothing - the "Cooperstown Collection." The shop's book section features few, if any, critical collections and are largely nostalgic memoirs from hall of fame players and coaches. Although a small amount of the shop's collection focuses on the Negro Leagues, there are no items from women's baseball history. The gallery guides and museum shop workers also noted that the museum has acquired an adjacent retail space to expand the museum store.

Interestingly, much of the commerce exists outside of the museum itself, with numerous baseball memorabilia shops and baseball-themed restaurants within a block or two of the museum. Here, the focus of commercial outputs is much more narrow and reflects a narrower version of consumer demand (Figure 4). Most of the memorabilia stores focus on large baseball markets and popular teams such as the New York Yankees, Boston Red Sox, Chicago Cubs, and St. Louis Cardinals. There also appears to be little trade in other forms of baseball memorabilia from the Negro Leagues, from other baseball leagues (such as Japan), or from women's baseball. Of particular note is that there is a commercial market for memorabilia from players not inducted into the hall of fame (such as more recent players or players without a hall of fame pedigree) and players, such as Pete Rose, who are banned from the NBHF. 
Figure 4 - The "Baseball Nostalgia" shop in Cooperstown is representative of the larger commercial approach to baseball heritage outside of the hall of fame. Photo by (removed for review)

\section{Discussion}

Museums of all types have to find ways of striking a balance between their cultural and economic roles. Sports museums, in particular, are called upon to both accurately and authentically represent the sporting past as well as generate revenue for both the institution itself and the surrounding community. However, given that more critical or challenging narratives do not often correspond with economic outputs, most sports museums tend to engage more with nostalgic and uncritical narratives in order to meet their financial objective. We found that the NBHF was able to balance both critical approaches to baseball's heritage as well as nostalgic veneration of baseball's past largely through spataially separating exhibits which approach the sport's past differently, as well as providing visitors opportunities and spaces for discussion, debate, and contemplation. Given that the NBHF continues to attract hundreds of thousands of visitors annually, as well as being integral to the continued commercial success of numerous local and regional businesses, the NBHF provides a template for oth sport and popular culture museums who may be reluctant to include critical narratives lest it adversely impact commercial operations.

Interestingly, the NBHF appears to view its role as both temple and forum, though these roles are spatially delineated. The museum would lack any sort of authenticity and gravitas if it did not address the "elephant in the room" in terms of PEDs, gambling, labour issues, and illicit 
drug use. Undoubtedly, visitors to the museum are sophisticated enough to both expect that these issues will be addressed, perhaps want to address these issues themselves with gallery guides, and provide space for memory, nostalgic reflection, and admiration. From an economic standpoint, a balance between more critical perspectives and nostalgic narratives may, in fact, attract diverse audiences or support memberships to the museum. However, the fact that the direct commercial arm of the museum - specifically the store - is predominantly, if not exclusively, nostalgia-driven suggests that the clear commercial appeal lies with uncritical reflection. Similarly, the museum appears to have deferred additional economic outputs to the surrounding town, although without the museum's presence these retail outlets would struggle to survive.

There is little doubt that the museum is one of the more prominent hallmark venues in North America - that is, a visitor attraction that is synonymous with the destination. Cooperstown has become an accepted metonym, not only for the museum and hall of fame, but also for the traditions and integrity of the game. A heritage environmental congruency exists between place and attraction that continues to impact upon the secondary economic developments of the village, as well as the design and presentation of baseball in the NBHF. It is unclear to what extent the cultural and political features of Cooperstown has directly and/or indirectly influenced the manner in which the sport is interpreted, and the administrative decisions made at the NBHF, though there is little doubt that the village's heritage helps to underpin the authenticity of the exhibits and the history of the game.

Reflecting on Phillips (2012) sports museum typology then, we can see that the NBHF represents a hybrid of sorts between the public and corporate museum. Clearly, the museum has reached a stage in terms of fame and reputation to be able to incorporate more challenging 
heritages while also maintaining its central purposes: a celebration of baseball's past, a pilgrimage center for baseball fans, and a repository for baseball heritage and artefacts. Its infamy is appealing not only to baseball fans, who likely have it high on their list of places to visit, but also to non-baseball fans as well. A comparison between NBHF and large, globallyfamous museums such as the Smithsonian or British Museum is apt. Visitors may not necessarily go to these museums because of their contents as much as the fact that they are famous for being famous and, as such, these museums can present narratives which may not always be celebratory without the fear of necessarily losing public support.

Although the NBHF exisits in a privileged position in terms of its history, cultural relevancy, and commercial appeal, its narrative approach provides lessons for other museums and halls of fame, particularly those which represent sport and other forms of (recent) popular cultures which may be faced with a dichotomous decision to reporesent their collections critically or nostalgically. Seemingly, uncritical celebration and veneration may be viewed as the route to commercial success and relevancy, and yet the NBHF demonstrates that the incorporation of challenging heritages does not doom one to financial ruin. Indeed, there appears to be a commercial appeal for the incorporation of critical narratives. Audiences - whether they be sports fans, museum visitors, tourists, or consumers of popular culture - are increasingly sophisticated, and the interpretive approach taken by NBHF appears to both respects and acknowledges this sophistication. The very fact that the NBHF interpretes the flaws in its own foundation - as seen through the interpretation of Doubleday myth - as well as the fact that many of the heroes it celebrates as well as the sport it venerates are, nevertheless, flawed, demonstrates an approach more sport and popular culture museums ought to consider. Like Davies et al (2013), we acknowledge that this approach is not easy - indeed, contemporary 
museums are narratively pulled in many different directions, often simultaneously. However, such an approach should be considered for museums looking to have continued cultural relevancy, credibility, and commercial success.

Perhaps the significant challenge that the NBHF has in balancing cultural and economic aims lies in baseball's popularity, particularly in the United States. Although baseball could long claim to be America's most popular sport, football has long eclipsed it in terms of popularity amongst spectators while soccer likely has more participants at youth levels than does baseball. The fact that NBHF attendance has waned in recent years perhaps reflects broader challenges about baseball's cultural place in the United States rather than the appeal of the NBHF in particular. Going to the NBHF requires effort due to its geographical location and, perhaps, fewer people are willing to make that effort. Should attendance to the museum consistently drop, the balance between cultural and economic outputs would have to be examined. As it stands, the NBHF exists in a relatively privileged position, in part through its own mythology, of how it interprets baseball's heritage. Whether this might change, and what might influence these changes, requires further examination.

The research for this paper was made possible by a grant from (removed for review) 
Allen, M. P. \& Parsons, N. L. (2006). The institutionalization of fame: achievement, recognition, and cultural consecration in baseball. American Sociological Review, 71(5), 808-825.

Anania, J. (2016). Main Street Metamorphosis: The Impacts of Baseball Tourism in Cooperstown, New York. Middle States Geographer, 49, 84-91.

Bagnall, G. (2003). Performance and performativity at heritage sites. Museum and society, 1(2), 87-103.

Bailey, C.A. (2007). A Guide to Qualitative Research (2nd ed.). London: Sage.

Barrett, M. S. and Mills, J. (2018) The Inter-reflexive possibilities of dual observations: an account from and through experience. International Journal of Qualitative Studies in Education, Vol.22, No.4, pp. 417- 429.

Barringer, T. \& Flynn, T. (1998) Colonialism and the Object: Empire, Material Culture and the Museum. London: Routledge.

Blinde, E. M., \& McCallister, S. G. (2003). Observations in the National Baseball Hall of Fame and Museum: doing gender in Cooperstown. Research quarterly for exercise and sport, 74(3), 301-312.

Bloom, B.M. (2018, July 29). Baseball Hall of Fame Induction Draws Second-Largest Crowd Ever to Cooperstown, N.Y. Forbes. Retreived from

https://www.forbes.com/sites/barrymbloom/2018/07/29/baseball-hall-of-fame-induction-drawssecond-largest-crowd-ever-to-cooperstown-n-y/\#247dd55f5ddb

Davies, S. M., Paton, R., \& O'Sullivan, T. J. (2013). The museum values framework: a framework for understanding organisational culture in museums. Museum Management and Curatorship, 28(4), 345-361.

Falk, C. G. (2012, October). When Tourism Is History: Travel and the Construction of the Past in Cooperstown, New York. In Buildings \& Landscapes: Journal of the Vernacular Architecture Forum (Vol. 19, No. 2, pp. 1-19). Minneapolis: University of Minnesota Press.

Friss, E. J. (2006). From university heights to cooperstown: Halls of fame and American memory. Journal of Archival Organization, 3(4), 87-104.

Fyfe, D. A. (2008). Birthplace of baseball or village of museums? The packaging of heritage tourism in Cooperstown, New York. Journal of Sport \& Tourism, 13(2), 135-153.

Kelly, J. D. (2007). Making the world safe for Baseball: Reflections on internationalism in Cooperstown and the World Baseball Classic. The International Journal of the History of Sport, 24(2), 215-237. 
Gould, S. J. (1989). The creation myths of Cooperstown. Natural History, 11, 14-24.

Graham, B. (2002). Heritage as knowledge: capital or culture?. Urban studies, 39(5-6), 10031017.

Graham, B., Ashworth, G.J., \& Tunbridge, J.E. (2000). A Geography of Heritage: Power, Culture \& Economy. London: Arnold.

Misiura, S. (2006). Marketing Heritage. London: Elsevier.

Newman, R. (2001). The American church of baseball and the National Baseball Hall of Fame. NINE: A Journal of Baseball History and Culture, 10(1), 46-63.

Nightengale, B. (2017, January 18). Ivan Rodriguez, Tim Raines and Jeff Bagwell prove Hall of Fame does forgive. USA Today. Retreived from https://www.usatoday.com/story/sports/mlb/columnist/bob-nightengale/2017/01/18/baseballhall-of-fame-ivan-rodriguez-jeff-bagwell-tim-raines-steroid-era/96742034/

Ogden, D. C. (2007). Major league baseball and myth making: Roland Barthes's semiology and the maintenance of image. NINE: A Journal of Baseball History and Culture, 15(2), 66-78.

Patton, M.Q. (2002). Qualitative Research \& Evaluation Methods (3rd ed.). Sage: Thousand Oaks.

Pearce, S. M. (1992) Museums, Objects and Collections. Leicester: Leicester University Press.

Phillips, M.G. (2012). Introduction: Historians in Sport Museums. In M.G. Phillips (ed.), Representing the Sporting Past in Museums and Halls of Fame (pp. 1-28). London: Routledge.

Phillips, M. G., Osmond, G., \& Morgan, S. (2014). Indigenous sport and heritage: Cherbourg's Ration Shed Museum. Journal of Heritage Tourism, 9(3), 212-227.

Ram, Y., Bjork, P. \& Weidenfeld, A. (2016) Authenticity and Place Attachment of Major Visitor Attractions. Tourism Management, 52, pp. 110-122.

Ramshaw, G. \& Gammon, S. (2005). More than just Nostalgia? Exploring the Heritage/Sport Tourism Nexus. Journal of Sport \& Tourism, 10 (4), 229 - 241.

Slater, D. (2006). Analysis Cultural Objects: Content Analysis and Semiotics. In J. Scott (Ed.), Documentary Research: Volume I (pp. 119-134). London: Sage.

Silverman, D. (2001). Interpreting Qualitative Data (2nd ed.). London: Sage.

Taylor, A. (1996). William Cooper's Town: Power and Persuasion on the Frontier of the Early American Republic (p. 119). New York: Vintage Books. 
Taylor, J. Z. and Rostron, K. I. (2018) The of a safety and quality culture assessment tool from a longitudinal, mixed-method research journey. Worldwide Hospitality and Tourism Themes, Vol.10, No.3, pp. 313-329.

Vamplew, W. (1998). Facts and artefacts: Sports historians and sports museums. Journal of Sport History, 25(2), 268-282.

Veal, A.J. (2006). Research Methods for Leisure and Tourism (2nd ed.). London: Prentice Hall.

Von Burg, R., \& Johnson, P. E. (2009). Yearning for a past that never was: Baseball, steroids, and the anxiety of the American dream. Critical Studies in Media Communication, 26(4), 351371.

Wang, N. (1999). Rethinking authenticity in tourism experience. Annals of tourism research, 26(2), 349-370.

Williams, D. R. (2002) Leisure Identities, Globalization, and the Politics of Place. Journal of Leisure Research, 34(4), pp. 351-367.

Yin, R. K. (1994). Case study research: design and methods. Thousand Oaks, CA: Sage

Yuksel, A., Yuksel, F. \& Bilim, Y. (2010) Destination Attachment: Effects on Customer Satisfaction and Cognitive, Affective and Conative Loyality. Tourism Management, 21(2). Pp. 274-284

Weed, M. (2017) Capturing the essence of grounded theory: the importance of understanding commonalities and variants. Qualitative Research in Sport, Exercise and Health, Vol. 9, No. 1, pp. 149-156. 